\title{
Jute Plant- A Bio-Degradable Material in Making Sanitary Pad for Sustainable Development
}

\author{
${ }^{1}$ Comfort Afi Agbaku ${ }^{*}{ }^{2}$ Alimatu Sadia Yahaya, ${ }^{3}$ Feng Junhua, ${ }^{4}$ Shi Chengqi, ${ }^{5}$ Wangkung Linda \\ ${ }^{1,2}$ School of Economics and Management, Shaanxi University of Science and Technology, research \\ direction: Entrepreneurship and Strategy, Innovation, sustainable development \\ ${ }^{3,5}$ School of Economics and Management, Shaanxi University of Science and Technology, engaged in \\ corporate management and technical economics and management research \\ ${ }^{4}$ School of Economics and Management, Shaanxi University of Science and Technology, engaged in \\ Innovation and entrepreneurship research
}

\begin{abstract}
This Purpose: Achieving Environmental Sustainability by increasing access to affordable, biodegradable, and healthy sanitary napkins, the paper aims to shed light on the use of the Jute Plant in place of the chlorine-bleached wood pulp or cotton and packaging.

Design/Methodology/Approach: The research is developed based on results drawn from a survey on women (both workers and student) and secondary data collected from researches, papers written on female hygiene, Sustainable development goals, and Research Institute on Jute Plant.
\end{abstract}

Findings: The jute plant can be used to replace the non-biodegradable materials used in making sanitary napkins and that many women are ready to change their napkins for many cost-effective and biodegradable ones.

Value: Creating a platform for women to have access to affordable sanitary napkins and conserve the environment. Contributing to sustainable development by positioning the environment in its original state after use.

Keywords: Jute Plant, Bio-Degradable and Non-Biodegradable, Sanitary Napkins, Hygiene, Sustainability.

\section{Introduction}

Menstruation is a natural and healthy cycle in a woman's life in which, the first period can be deemed as an achievement celebrated by in some cultures. But there are some menstrual taboos and period shaming that comes with the impact of the products we use and how we dispose of them. This, in turn, leads to some health problems as it can pollute our environments or be disposed of in landfills.

Over the decade women's health and hygiene have been of crucial concerns throughout the world and also there is lacking awareness of menstrual hygiene and usage of sanitary napkins in some rural areas. Poor menstrual hygiene can cause fungal infections, repeated infections leading to urinary tract infection, cervical cancer, and vulnerable to infertility.

The average menstrual cycle ranges from 3-7days from ages 13- 51. The average woman endures some 1,368-3,192 total periods over 38 years of her life. Due to this fact, there is a high demand for sanitary pad day in and out. A report in the LONDONASSEMBLY by the environment committee, on the single-use Plastics unflushables, stated that an estimated $200 \mathrm{~kg}$ of the menstrual product is disposed of in an average person's lifetime (Commitee, 2018). It is estimated that a pad is composed of $90 \%$ plastic, hence a pack of menstrual pads is the same as 4 plastic bags which can also be found in tampons, the string, and plastic applicators that are made from polyethylene (PE) and polypropylene (PP). (Friends of the Earth, 2018)

There is a massive waste of carbon footprint left behind by the feminine hygiene product. According to Menstrual Health Alliance India, the life span of one sanitary pad can take about 500-800 years because of the non-biodegradable nature of the plastic which is dumped into a landfill, releasing gases harmful to our 
health (Barman, 2017). Most companies focused on making sanitary pads but fail to take into account the effect of its disposal on the environment. Therefore, Using the Jute fiber is not just about producing sanitary pads but producing organic and biodegradable sanitary pads.

\section{Jute and Sustainable Development}

The impact of sanitary waste on the environment has been of major concern today, and to curb this concern is to focus on making a product that has a low carbon footprint. This is because the natural resource materials used in making these sanitary pads are mostly petroleum-based which is hard to reuse or degrade. And most importantly, there is no sustainable development due to the over-exploitation of this resource. For there to be sustainability there has to be an alternative raw material that will not compromise the functional requirement of the product.

Jute is the plant or fiber used to make burlap, hessian or gunny cloth, produced primarily from plants in the genus Corchorus, which is classified with the family Tiliaceae. Jute is a long, soft, shiny vegetable fiber that can be spun into coarse, strong threads (Wikimedia foundation. Inc, 2019).

It is one of the most affordable natural fibers, second only to cotton in its production and uses. Jute fibers are composed primarily of the plant materials cellulose and lignin. Jute is also called the golden fiber for its color and high cash value.

Production is concentrated mostly in Bangladesh, India, Pakistan, and China while the United Kingdom, Japan, United States, France, Spain, Ivory Coast, Germany, and Brazil import a significant quantity of jute fiber and products from Bangladesh.

Jute fabrics are carbon-dioxide neutral and decompose naturally. Hence, making it the most environmentally friendly fiber from its seed to its expired fiber, which can be recycled more than once. (Wikipedia, 2019).

\section{Layers of Sanitary Pads, Composition, and Effect of Poor Disposal Practices}

The sanitary pad is a wide product which resistant to liquid contains layers of quilted cotton materials with layers of super absorbent. According to the latest report Group, "Sanitary Napkin Market: Global Industry Trends, Share, Size, Growth, Opportunity and Forecast 2018-2023", the global sanitary napkin market reached a value of US\$19.5 Billion in 2017. Several factors are owing to which sanitary napkins have emerged as one of the most popular options for menstrual management (Research and market, 2018).

An advancement in economic development and boosting market conditions has opened the door for a higher number of women across the world to afford sanitary napkins. Even though, the situation might vary in developed and developing regions. Also, there has been a significant increase in the demand for hygienic products due to an immerse awareness of the benefits of using this product through public education, promotions, and initiatives by the government, sanitary-making companies, and NGOs. Below is an outline of the layers of a sanitary pad.
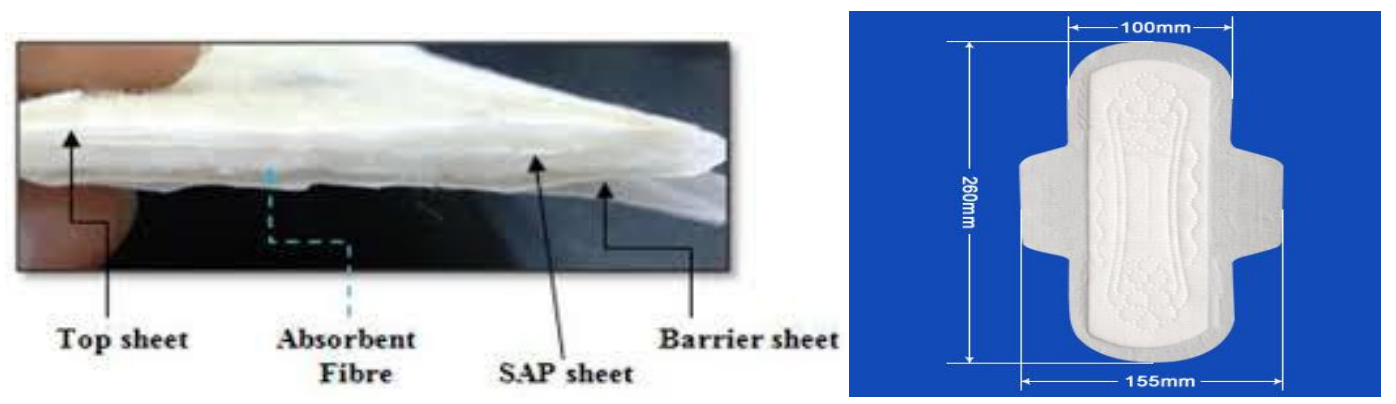

Source: Barman et al., J Textile Sci Eng. 2017, 7:3

a) The top sheet (Acquisition Layer-perforated film, polypropylene): It is designed to transfer fluid quickly from the top sheet to secondary layers. The top sheet contains thermoplastic fibers to prevent the capillary collapse of this layer, and a small amount of hydrophilic absorbent fiber to allow fluid to absorb. The commercially available top sheet is made up of polypropylene fiber which is not environmentally friendly, but the jute fiber can replace the polypropylene used in making the top sheet. And as a top sheet, the jute fiber can be skin-friendly and will degrade when disposed of. 
b) The absorbent core (Absorbent core, SAP + Wood Pulp): It is interposed between the top sheet and barrier layer to absorb and retain fluid. Moreover, to have comfort, the absorbent core needs to be thin, soft, and pliable. The core was made up of wood pulp traditionally but there is constant effort to replace it by airlaid wood pulp and SAP to improve its absorption efficiency. SAP turns the absorbed liquid into a jelly-like state so that it would not retract back. (Woeller KE, 2015) (BS, 1992) The primary requirement of the sanitary pad is the absorbency of menstrual fluid and the jute fiber has a very high absorbent efficiency which can replace the wood pulp. Jute has a high cellulose content and water affinity with a shorter fiber length easing the preparation of the cellulose pulp.

c) Barrier sheet (Barrier Sheet, Polyethylene): It seals the fluid from staining or leakages. It is a breathable but fluid impermeable film made up of polyethylene. Few components of the sanitary pad will disintegrate and be attacked by the bacteria in a public or private sewage disposal system but polyethylene or polymeric films used as a barrier sheet remain intact as this polymer is inert and are not broken down by bacteria and thus pollutes the environment. (Shishoo, 1992) for the barrier sheet, polyethylene and polyurethane are the materials widely used but they are non-biodegradable plastic. Therefore with the jute plant, bio-based plastic can be made from it to replace Polyethylene and polyurethane. For example, the Jute polybag was invented by a scientist in Bangladesh using jute cellulose that is bio-degradable and bio-plastic (Pavel S., 2017).

The aim of this paper highlights the problem of non-biodegradable sanitary napkins which has become a threat to the environment. Prominence is given to the Jute fiber which is available with a low carbon footprint and also producing hygienic products that are highly sustainable to replace petroleum-based raw material with environmentally friendly ones. Few articles have been able to properly define what a safe disposal and management waste means. A reason could be the classification of menstrual waste such as solid waste, hazardous waste, or bio-medical waste, thus making disposal of such waste unclear, leading to unsuitable and dangerous ways of disposing of. (Hartmann, Krishnan, Rowe, Hossain, \& Elledge, 2015) (House, 2012) notes that menstrual hygiene friendly infrastructure includes "clear instruments for collecting and disposing of menstrual waste," but does not explain what the instruments could be.

Practicing good menstrual hygiene entails that women have access to clean menstrual management materials in absorbing menstrual blood, which should be changed as often as necessary during their menstrual period and having access to safe and convenient facilities in disposing of used menstrual materials. (Cooperation, 2016).

\section{Methodology, Results, and Analysis}

A simple survey was done to gather information on the female usage of sanitary products and other factors that affect female hygiene and how their disposal of these sanitary napkins pollutes the environment. The esurveycreator.com online survey form was used to gather such data and this paper is one of its own, concentrated on gathering data on the kind of sanitary napkins women used and if the given option of having one that's healthy, environmentally friendly and cost-effective, would they rather opt for that or stick to what they are accustomed to. This was mostly to have a general overview of some of the issues women encounter in their menstrual period and some of the techniques they use in solving these issues.

A total of 12 questions were given and out of the 100 participants the link was shared to; 60 people participated in giving a total of 988 answers.

Below is a summary of the data gathered and simple but effective analysis of results: 


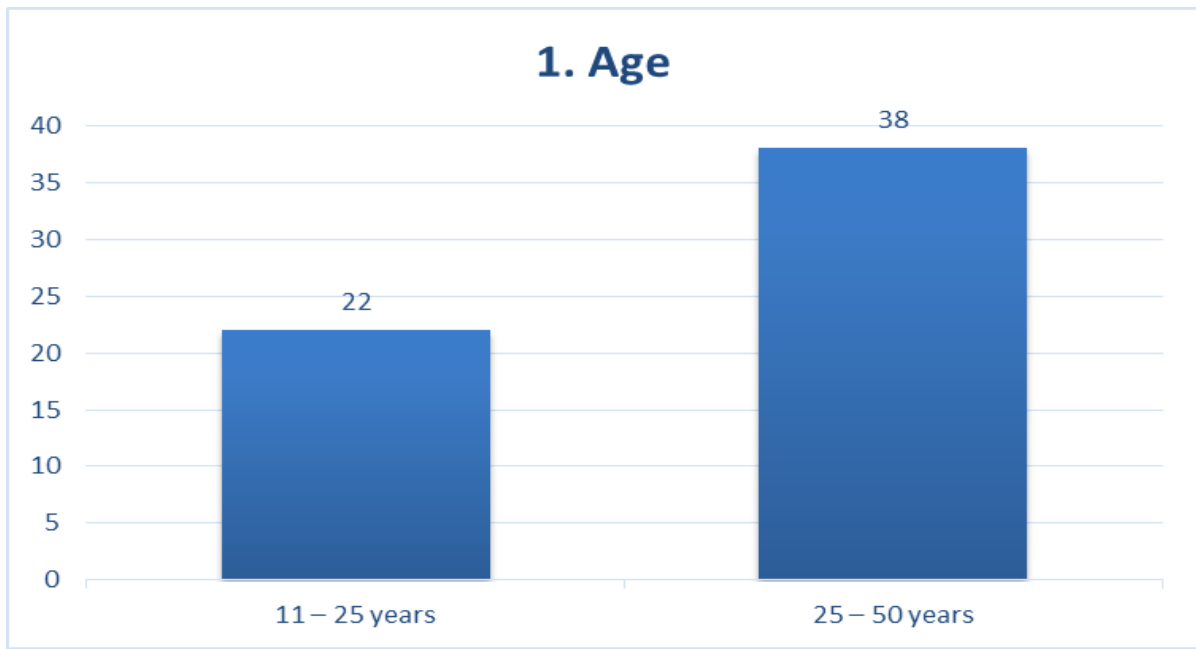

Figure 1:

The above figure shows the age range of the participants. We got 22 of them between 11-25years and 38 of them from 25-50years. This means that the majority of or participants are matured and experienced when it comes to female menstrual hygiene.

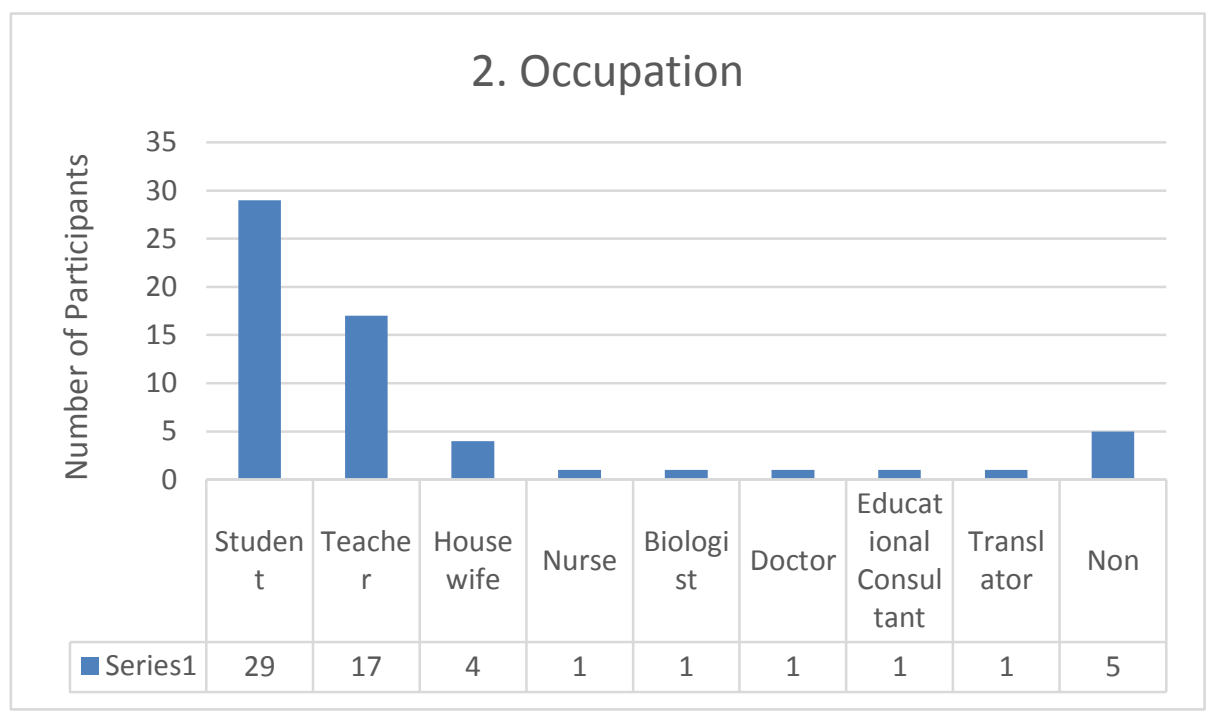

Figure 2:

As seen in the figure above, due to geographical constraint 22 of or participants are students, 17 teachers, 4 housewives, 1 biologist, doctor, education consultant, translator respectively, and 5 non-workers. But even with the limitation we still got a variety of occupations with different views on the issue at hand.

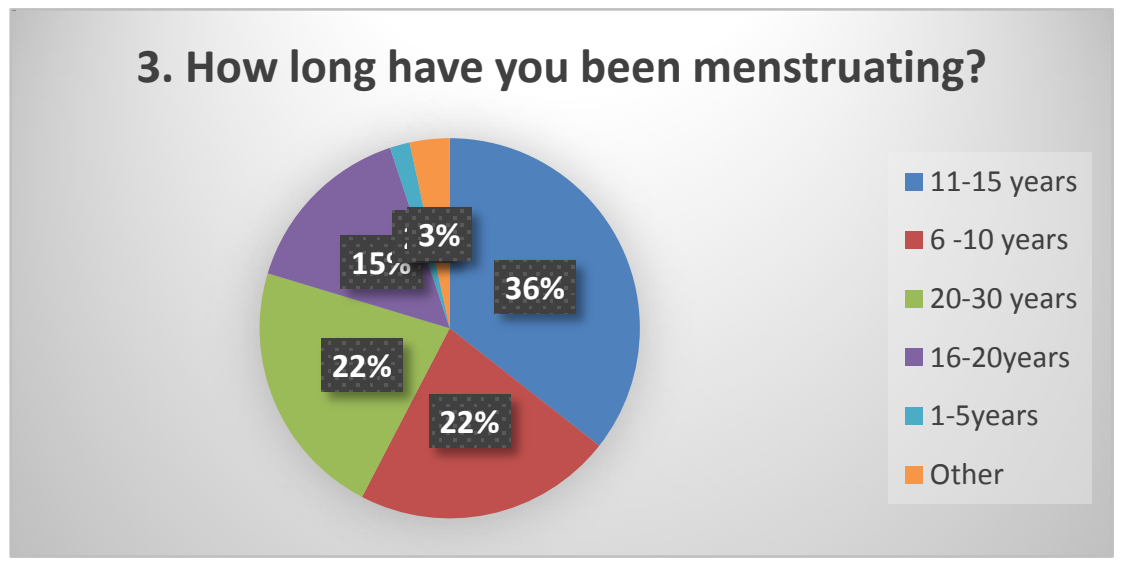

Figure 3:

The above figure illustrates the duration in which the participant has been menstruating and looking at the chart majority of them are between 11-15years. With those menstruating for a longer period between 20- 
30 years are $22 \%$. It can be deduced that some are more than 30years or less than 1year since $3 \%$ of them fall in the other category.

\section{What is your period length?}

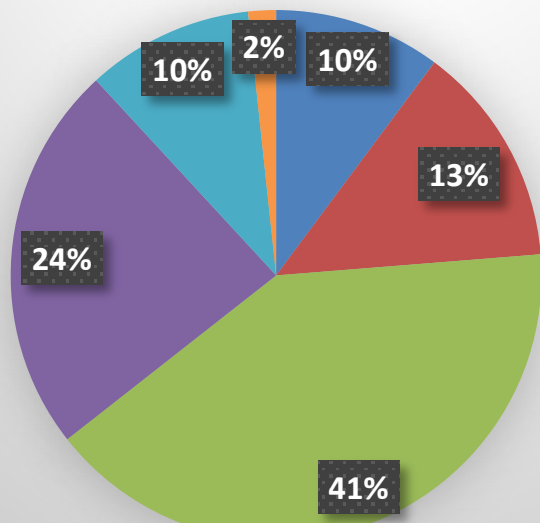

7 days

6 days

5 days

4 days

3 days

Other

Figure 4:

The above figure shows that more of the participant has their period length in 5days which can be considered as average days. The same goes for those that have a period length within 3 and 4days. It is not common too find many within 7 days, hence $13 \%$ of the participant fell within that sector.

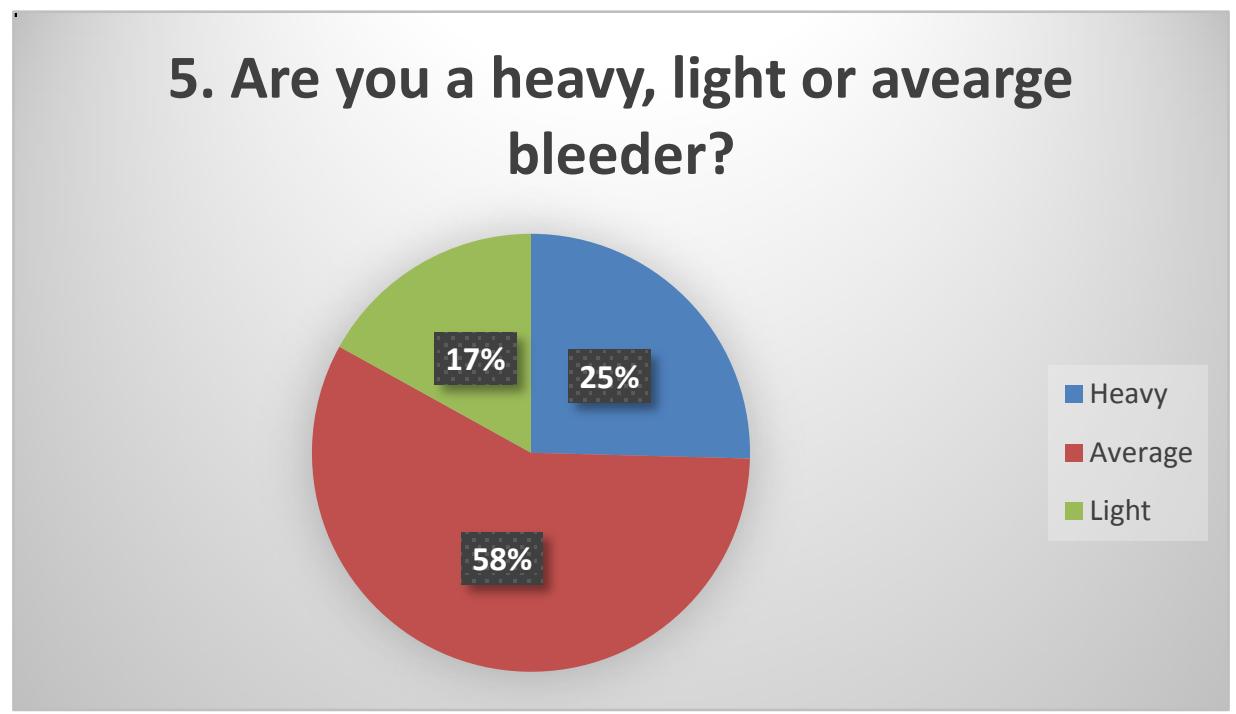

Figure 5:

In the above figure, $58 \%$ of our participants were average bleeders and $25 \%$ were heavy bleeders. The light bleeders were only $17 \%$. 


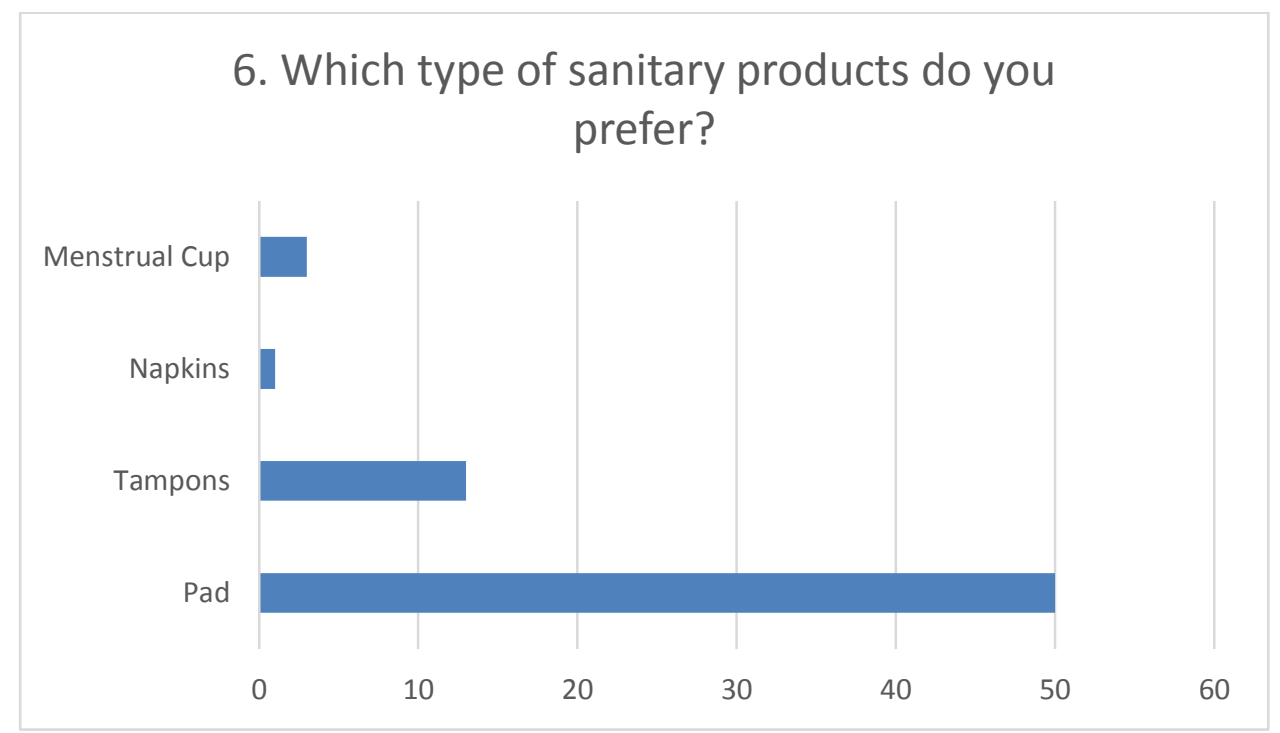

Figure 6:

50 of our participants preferred to use the sanitary pad out of the 60 with the rest going for either the tampons, napkins, or the menstrual cup. It can be seen that they prefer to use the cup and re-use it again than the napkins.

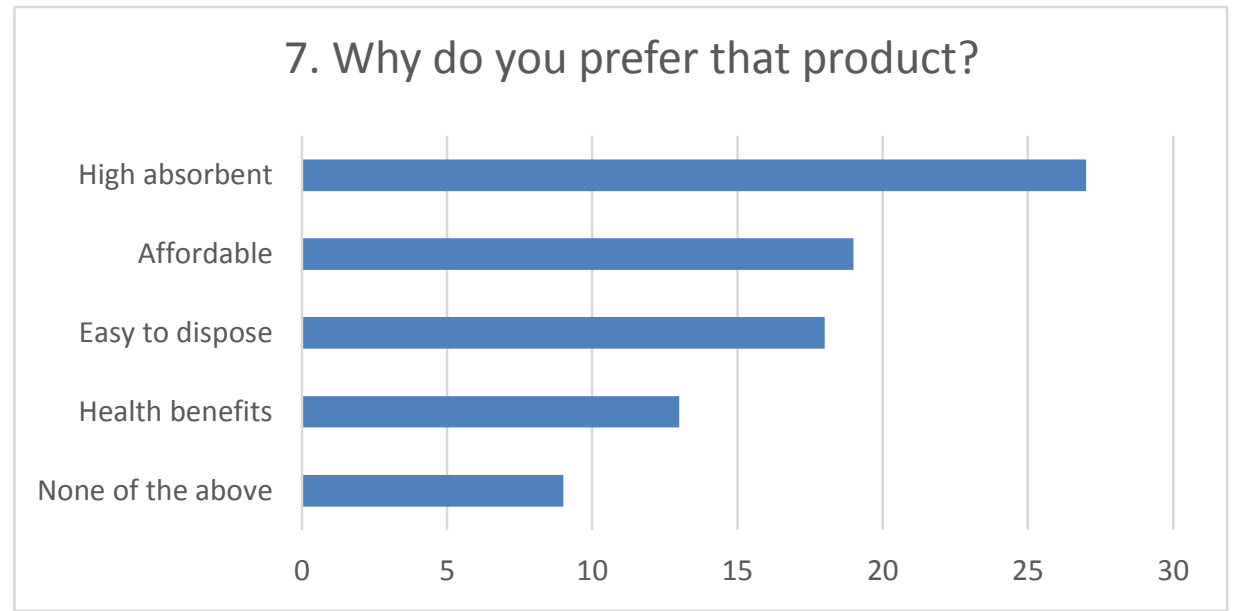

Figure 7:

The above figure was rated based on the likeability of their chosen product in figure 6, 27 of the participant uses their sanitary product because of its high absorbency, and 19 chose based on its affordability, 18 chose because it is easy to dispose of whiles 13 participants chose because of its health benefits. Even with the above category, 9 participants said none of the above was their reason for choosing the product.

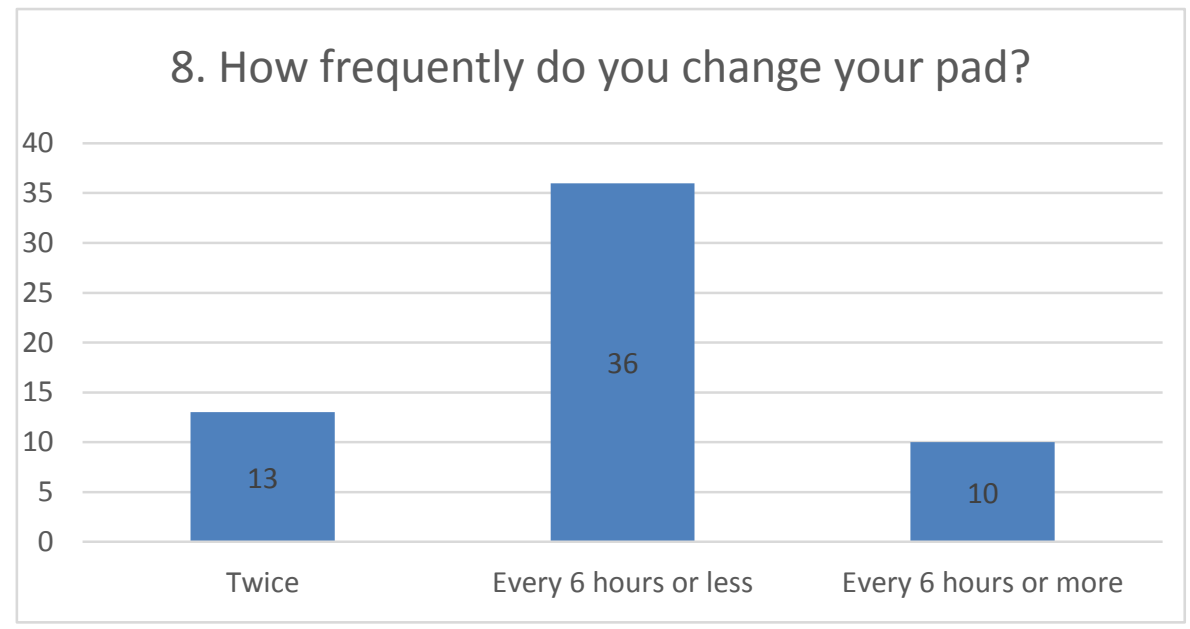

Figure 8: 
36 of the participants change their sanitary pads every 6hours or less which means using 3 or 4 sanitary pads in a day during menstruation, 10 of them change every 6 hours or more whiles 13 of them change it twice.

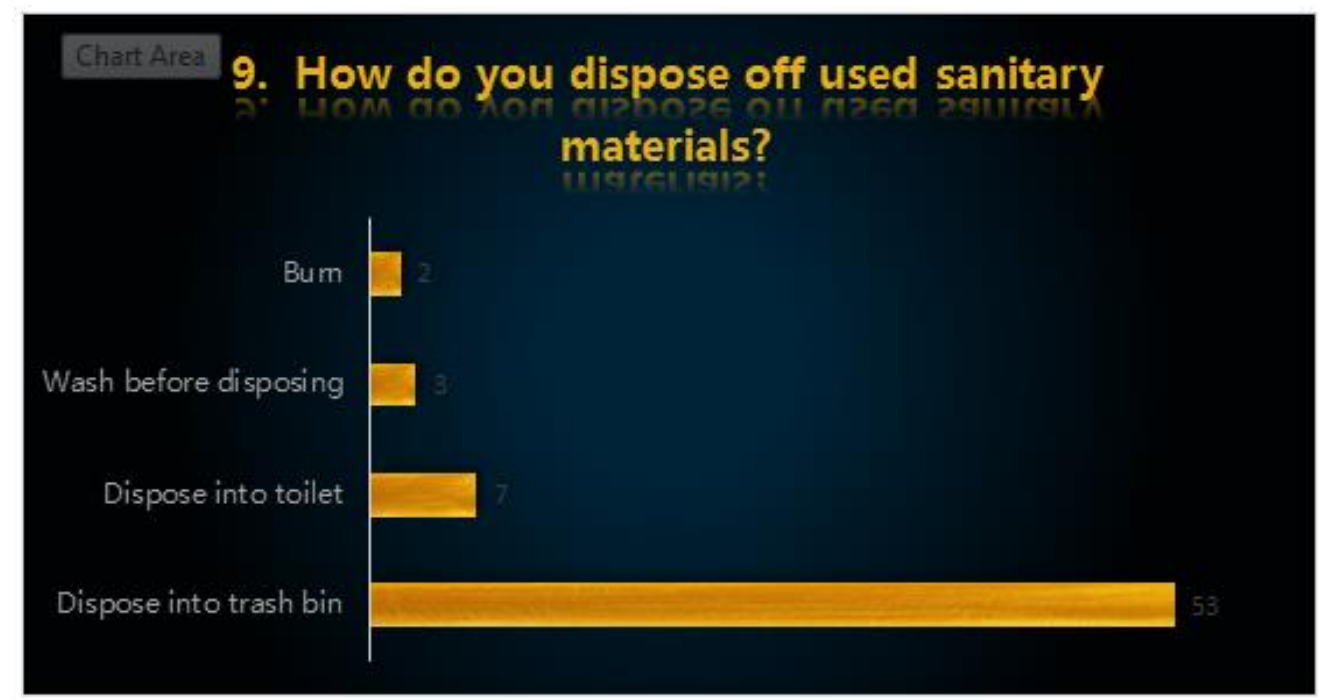

Figure 9:

Disposal of this product is mostly the primary concern of this paper. In the above illustration, 53 participants will dispose of their used sanitary pads into trash bins which is an excessive amount of waste. Others chose more than one way of disposing of their used materials but none of the above makes it easy on the environment.

10. How will you categorize the extent to which you will replace your sanitary pad used daily for a new one based on the following aspect?

\begin{tabular}{|c|c|c|c|c|c|c|c|c|c|c|c|c|c|c|}
\hline & $\begin{array}{l}\text { very high } \\
\text { (1) }\end{array}$ & & $\begin{array}{l}\text { fairly } \\
\text { high } \\
\text { (2) }\end{array}$ & & $\begin{array}{c}\text { average } \\
\text { (3) }\end{array}$ & & $\begin{array}{l}\text { fairly } \\
\text { low } \\
(4)\end{array}$ & & $\begin{array}{c}\text { very low } \\
(5)\end{array}$ & & $\begin{array}{l}\text { can't } \\
\text { say } \\
(6)\end{array}$ & & & \\
\hline & $\Sigma$ & $\%$ & $\Sigma$ & $\%$ & $\Sigma$ & $\%$ & $\sum$ & $\%$ & $\sum$ & $\%$ & $\Sigma$ & $\%$ & $\varnothing$ & \pm \\
\hline Affordability & $15 \mathrm{x}$ & 25.86 & $11 x$ & 18.97 & $25 \mathrm{x}$ & 43.1 & $2 x$ & 3.45 & 0 & 0 & $5 \mathrm{x}$ & 8.62 & 2.59 & 1.38 \\
\hline Non-toxic & $26 x$ & 44.07 & $10 x$ & 16.95 & $12 \mathrm{x}$ & 20.34 & $1 x$ & 1.69 & $5 x$ & 8.47 & $5 \mathrm{x}$ & 8.47 & 2.39 & 1.65 \\
\hline $\begin{array}{l}\text { Bio-degradable/ } \\
\text { environmental friendly }\end{array}$ & $23 x$ & 39.66 & $8 \mathrm{x}$ & 13.79 & $18 \mathrm{x}$ & 31.03 & $2 \mathrm{x}$ & 3.45 & $3 x$ & 5.17 & $4 \mathrm{x}$ & 6.90 & 2.41 & 1.51 \\
\hline High absorbent rate & $23 x$ & 39.66 & $15 x$ & 25.86 & $16 \mathrm{x}$ & 27.59 & $1 \mathrm{x}$ & 1.72 & 0 & 0 & $3 x$ & 5.17 & 2.12 & 1.26 \\
\hline odorless & $23 x$ & 38.98 & $10 \mathrm{x}$ & 16.95 & $17 \mathrm{x}$ & 28.81 & $4 \mathrm{x}$ & 6.78 & $3 x$ & 5.08 & $2 \mathrm{x}$ & 3.39 & 2.32 & 1.37 \\
\hline
\end{tabular}

\section{Figure 10.0}

Based on the ratings, a participant's choice as either very high, fairly high, average, fairly low, very low, or just no option at all. If a sanitary napkin is affordable, non-toxic, bio-degradablelenvironmentally friendly, high absorbent rate, and odorless, they will opt for it. Most of them rated very high on the above categories. 


\section{Do you think there are anxiety and stress associated with the management of menstrual waste? \\ no nes}

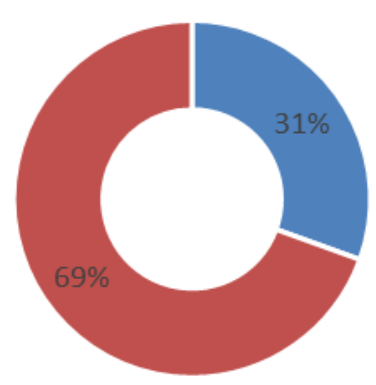

\section{Figure 11:}

The chart above shows that $69 \%$ of the participant find it very stressful to dispose of menstrual waste since it can be very difficult to know which method is the best and also good for the environment.

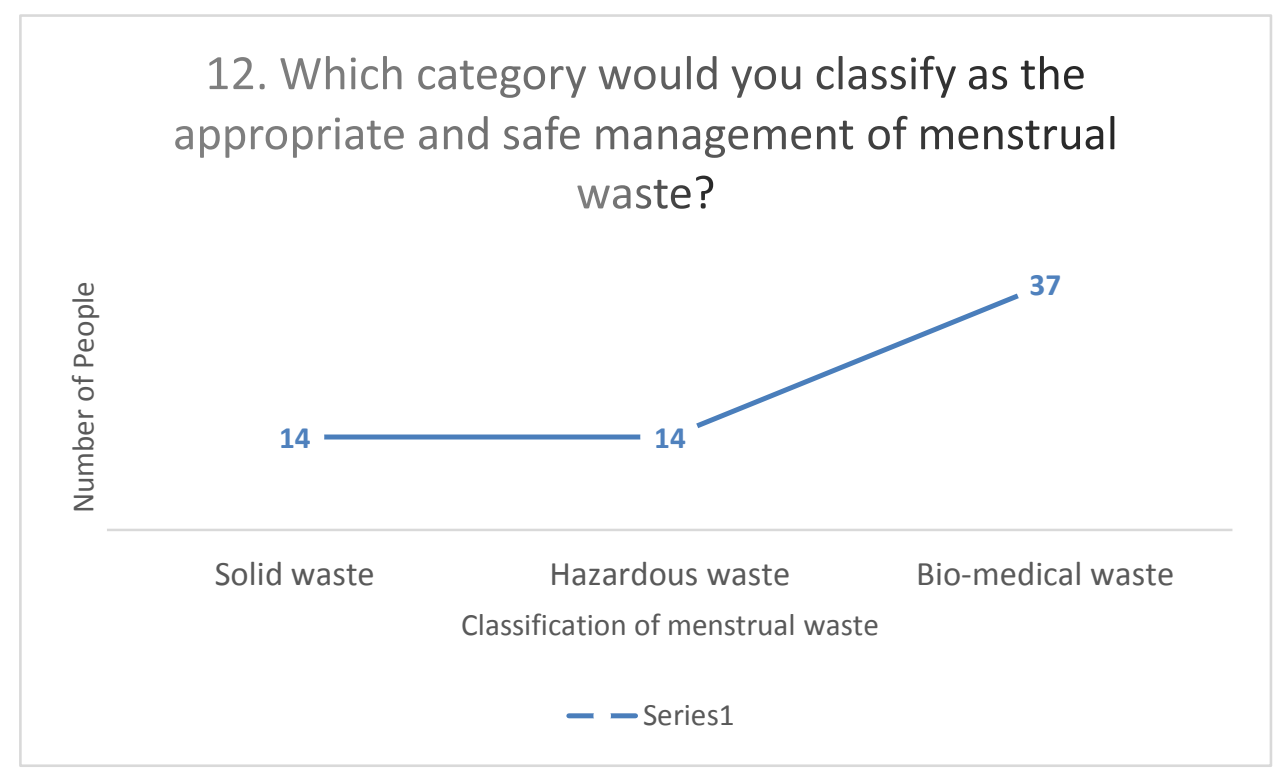

Figure 12:

This diagram is to find out if the participants know under which classification menstrual waste falls under. 37 of them think it's a bio-medical waste, 14 of them think its Hazardous, and 14 of them think it's a solid waste. This is basically to access their awareness of the health implication of menstrual waste and its effect on the environments and humans at large.

\section{Conclusion}

We find ourselves in an era where we take more from the earth but give less back. It is now affecting sustainability and development. Since the earth feeds and takes care of us, we must also do well by taking care of the hands that feed us. There needs to be a balance in what we take from the earth and what we give in return. There is a solution for every environmental problem out there and this is one way of solving a more pressing one.

Looking at the data gathered above, most women in this research change their sanitary napkins more than twice a day and if attention is given to such data, we can say that we have a lot to do because the amount of waste made by used sanitary materials is a big and urgent problem. But the good news is more women are opening up to the idea of using a pad that is eco-friendly and would cost them less but also healthy. We must work on it and provide women around the world with low-cost sanitary napkins affordable to all. 
The frequent use of Jute fiber in hygiene products will lead to an eco-friendly world.

As researchers who are concerned about the environment, we must find a sustainable system to provide a safer world for future generations.

\section{Acknowledgment}

We thank our supervisors and also Shaanxi University of Science and Technology for their guidance and support for without them this would not have been possible. Comfort Afi Agbaku writing, editing, data curation. Yahaya Alimatu Sadia writing, editing, data curation. Feng Junhua (Supervisor), Shi Chengqi (Supervisor), Wangkung Linda (Supervisor).

\section{Disclosure Statements:}

\section{Conflicts of Interests}

There is no conflict of interests

\section{References}

[1.] Barman A*, K. P. (2017). Natural and Sustainable Raw Materials for Sanitary Napkin. Journal of Textile Science \& Engineering, 3.

[2.] BS, G. (1992). Study of absorbency in Non-Woven: The role of structure and fluid characteristic. Papers of International Conference on Non-Woven. The Textile Institute North India Section.

[3.] Cooperation, S. I. (2016). Menstrual Hygiene Management. Agency SSIDC.

[4.] Friends of the Earth. (2018, Oct 15). Retrieved from https://friendsoftheearth.uk/plastics/plastic-periods-menstrual-products-and-plasticpollution.

[5.] GROUP, I. (2018). Sanitary Napkin Market: Global Industry Trends, Share, Size, Growth, Opportunity, and Forecast 2018-2023. Research and Markets.

[6.] Hartmann, M., Krishnan, S., Rowe, B., Hossain, A., \& Elledge, M. (2015). Gender-Responsive Sanitation Solutions in Urban India. NC, USA: RTI International: Research Triangle Park.

[7.] https://www.london.gov.uk/sites/default/files/plastics_unflushables_submited_evidence

[8.] House, S. (2012). Menstrual Hygiene Matters: A Resource for Improving Menstrual Hygiene around the World. WaterAid Report.

[9.] Pavel S. S. p. (2017). Bangladesh Invented Bio-plastic Jute Poly Bag and International Market Potentials. Open Journal of Business and Management, 624-640.

[10.] Shishoo, R. (1992). Analysis of structure- absorbency relationship in disposable hygienic products. Papers of International Conference on nonwovens. The Textile Institute North India Section.

[11.] Wikimedia Foundation.Inc. (2019, November 6). Retrieved from wikipedia.org/wiki/Jute: https://en.wikipedia.org/wiki/Jute

[12.] Woeller KE, H. K. (2015). Safety assessment of sanitary pads with a polymeric foam absorbent core. Regulatory Toxicology and Pharmacology. 